\title{
Editorial
}

\section{Basophils and Allergy}

The role of the basophil in health and disease has long remained an enigma. Basophils are the least abundant granulocytes in the blood, barely reaching $1 \%$ of the total leukocyte population. Like mast cells, basophils express the tetrameric form ( $\left.\alpha \beta \gamma_{2}\right)$ of the high affinity receptor for immunoglobulin E (IgE) FceRI [1]. Basophils also express a variety of other surface receptors that can lead to their activation (e.g. CD123, TLR4, Fc $\gamma$ RIII) [2] as well as inhibitory receptors, like the Fc $\gamma$ RIIB, that dampen their activation [3]. FceRI stimulation of basophils induces, as in mast cells, the immediate release of preformed pro-inflammatory mediators (such as histamine and proteases) and the later production and secretion of leukotrienes, cytokines and chemokines (such as IL-4, IL-5, IL-8, IL-10 and IL-13). These responses (both immediate and delayed) are potentiated with IL-3 preincubation of the cells $[2,4]$. Unlike the mast cell, basophils are normally not found in tissues, but their numbers can increase both in the blood of atopic patients as well as in situ where allergic inflammation is occurring (airways of asthmatic patients, skin of patients with atopic dermatitis, nasal mucosa of patients with allergic rhinitis) [4-6]. Basophils are able to produce and release multiple mediators involved in the symptoms of both acute and chronic allergic inflammations, such as histamine, IL-4, IL-13, and leukotriene C4 [7]. Although basophils are not the only cells producing these products, they are the only cells found in situ prior to the chronic phase of allergic diseases with the ability to quickly produce significant amount these mediators [4]. Additionally, the basophil is the main producer of IL-4 and IL-13 in peripheral blood following the challenge of asthmatic patients [4].

Because the basophil shares some molecular and functional features with the mast cell, and both cell types have been linked to allergy, it has long been viewed as "redundant circulating mast cells". Over the past forty years, considerable effort has been made towards defining the distinct immunological role of basophils. For the most part, these studies were incomplete as they primarily focused on animal models of allergy, such as in guinea pigs, or the study of patho-physiological conditions in human allergic responses. Nonetheless, this seminal work identified the basophil as an important player in pathologies like asthma, allergic diseases and parasitic infections [8-10]. A better understanding of the distinct immunological role of the basophil has more recently evolved through several major advances: The identification of cell surface markers that allow one to distinguish the basophil from other cell types as well as to determine the basophils' state of activation has allowed unambiguous identification and determination of their activity in vitro and in vivo [11-13]. The development of novel methods to purify human basophils to a high degree from the blood has facilitated in vitro molecular and functional studies [14-17]. The recognition that mice also have basophils [18-20], and the demonstration that in mice these cells can present antigen and promote Th2 cell differentiation [21-26] and responses has ushered in an era of the basophil as a regulatory cell. The demonstration of a distinct role for basophils in mouse models of chronic cutaneous allergic inflammation and IgG-mediated anaphylaxis [27-29] has promoted the understanding that the basophil has roles that are distinct from the mast cell in pathological responses. Collectively, these efforts have ushered in a new era in the study of basophils in health and disease.

This "Hot Topic" issue captures many of these recent advances and provides a brief summary of this evolving field. Herein, Mark Siracusa and David Artis review the recent and exciting discovery of basophils as initiating and sustaining type 2 responses, from studies conducted primarily on mice. The findings reviewed argue that the basophil is able to function as an antigen presenting cell and foster $\mathrm{T}$ and $\mathrm{B}$ cell help. Peter Valent describes the recent discovery of cell surface markers that are key in the identification and biology of basophils. Many of these define new modes by which basophils can be activated and the clinical implications of this information from studies on human basophils is discussed. Donald MacGlashan provides novel insights on the connection between human basophil maturation, the signaling elements expressed and the functional correlates that define distinct basophil populations. This information is important towards understanding the molecular underpinnings and the heterogeneiety of basophils. Lama Youssef and colleagues provide an excellent clinical perspective in the discussion of distinct basophil phenotypes in the context of therapy in allergic diseases, and review their findings in a long-term study of asthmatic subjects with omalizumab, a humanized monoclonal antibody that scavenges circulating IgE. Hajime Karasuyama and colleagues discuss their recent seminal work, primarily from mouse models, demonstrating distinct roles of basophils in allergic disease; work that clearly defines a separate and non-redundant niche for basophils. In the final chapter, Nicolas Charles and I discuss the findings of studies that extend the pathological role of basophils beyond allergy. This work makes it clear that basophils must be viewed to have regulatory functions and to play a role in autoimmunity. It shows that self-reactive IgEs and basophils are intimately linked to the amplification of autoantibody production in lupus and opens new avenues with therapeutic potential in lupus.

Collectively, this "Hot Topic" issue summarizes much of the recent advances in understanding basophil biology and function, particularly in disease. It should be noted, however, that this compilation of articles is not all encompassing and should not be viewed as definitive compendium. Instead, it is intended to provide a glimpse into a rapidly evolving field that 
continues to uncover new roles for basophils in allergic diseases and beyond. It is my hope that both the clinician and scientist alike find this "Hot Topic" issue on "Basophils and Allergy" to be of benefit.

\section{REFERENCES}

[1] Kinet JP. The high-affinity IgE receptor (Fc epsilon RI): from physiology to pathology. Annu Rev Immunol 1999; 17: 931-72.

[2] Min B. Basophils: what they 'can do' versus what they 'actually do'. Nat Immunol 2008; 9: 1333-9.

[3] Zhu D, Kepley CL, Zhang M, Zhang K, Saxon A. A novel human immunoglobulin Fc gamma Fc epsilon bifunctional fusion protein inhibits Fc epsilon RI-mediated degranulation. Nat Med 2002; 8: 518-21.

[4] Schroeder JT, Kagey-Sobotka A, Lichtenstein LM. The role of the basophil in allergic inflammation. Allergy 1995; 50: 463-72.

[5] Howarth PH, Salagean M, Dokic D. Allergic rhinitis: not purely a histamine-related disease. Allergy 2000; 55 Suppl 64: 7-16.

[6] Marone G, Triggiani M, de Paulis A. Mast cells and basophils: friends as well as foes in bronchial asthma? Trends Immunol 2005; $26: 25-31$.

[7] Min B, Paul WE. Basophils and type 2 immunity. Curr Opin Hematol 2008; 15: 59-63.

[8] Falcone FH, Pritchard DI, Gibbs BF. Do basophils play a role in immunity against parasites? Trends Parasitol 2001; 17: 126-9.

[9] Knol EF, Mul FP, Lie WJ, Verhoeven AJ, Roos D. The role of basophils in allergic disease. Eur Respir J 1996; Supplement 22: 126s-131s.

[10] Lichtenstein LM, Bochner BS. The role of basophils in asthma. Ann N Y Acad Sci 1991; 629: 48-61.

[11] Buhring HJ, Streble A, Valent P. The basophil-specific ectoenzyme E-NPP3 (CD203c) as a marker for cell activation and allergy diagnosis. Int Arch Allergy Immunol 2004; 133: 317-29.

[12] Valent P. Immunophenotypic characterization of human basophils and mast cells. Chem Immunol 1995; 61: 34-48.

[13] Valent P, Bettelheim P. Cell surface structures on human basophils and mast cells: biochemical and functional characterization. Adv Immunol 1992; 52: 333-423.

[14] MacGlashan DW, Jr Lichtenstein LM. The purification of human basophils. J Immunol 1980; 124: 2519-21.

[15] Warner JA, Reshef A, MacGlashan DW Jr. A rapid Percoll technique for the purification of human basophils. J Immunol Methods 1987; 105: 107-10.

[16] Kepley CL, Youssef L, Andrews RP, Wilson BS, Oliver JM. Syk deficiency in nonreleaser basophils. J Allergy Clin Immunol 1999; 104: $279-84$.

[17] Youssef LA, Schuyler M, Gilmartin L, et al. Histamine release from the basophils of control and asthmatic subjects and a comparison of gene expression between "releaser" and "nonreleaser" basophils. J Immunol 2007; 178: 4584-94.

[18] Dvorak AM, Seder RA, Paul WE, Kissell-Rainville S, Plaut M, Galli SJ. Ultrastructural characteristics of Fc epsilon R-positive basophils in the spleen and bone marrow of mice immunized with goat anti-mouse IgD antibody. Lab Invest 1993; 68: 708-15.

[19] Seder RA, Paul WE, Dvorak AM, et al. Mouse splenic and bone marrow cell populations that express high-affinity Fc epsilon receptors and produce interleukin 4 are highly enriched in basophils. Proc Natl Acad Sci U S A 1991; 88: 2835-9.

[20] Paul WE. Interleukin-4 production by Fc epsilon R+ cells. Skin Pharmacol 1991; 4 Suppl 1: 8-14.

[21] Sokol CL, Barton GM, Farr AG, Medzhitov R. A mechanism for the initiation of allergen-induced T helper type 2 responses. Nat Immunol 2008; 9 : $310-8$.

[22] Sokol CL, Chu NQ, Yu S, Nish SA, Laufer TM, Medzhitov R. Basophils function as antigen-presenting cells for an allergen-induced T helper type 2 response. Nat Immunol 2009; 10: 713-20.

[23] Perrigoue JG, Saenz SA, Siracusa MC, et al. MHC class II-dependent basophil-CD4+ T cell interactions promote T(H)2 cytokine-dependent immunity. Nat Immunol 2009; 10: 697-705.

[24] Yoshimoto T, Yasuda K, Tanaka H, et al. Basophils contribute to T(H)2-IgE responses in vivo via IL-4 production and presentation of peptide-MHC class II complexes to CD4+ T cells. Nat Immunol 2009; 10: 706-12.

[25] Charles N, Watford WT, Ramos HL, et al. Lyn kinase controls basophil GATA-3 transcription factor expression and induction of Th2 cell differentiation. Immunity 2009; 30: 533-43.

[26] Denzel A, Maus UA, Rodriguez Gomez M, et al. Basophils enhance immunological memory responses. Nat Immunol 2008; 9: 733-42.

[27] Mukai K, Matsuoka K, Taya C, et al. Basophils play a critical role in the development of IgE-mediated chronic allergic inflammation independently of T cells and mast cells. Immunity 2005; 23: 191-202.

[28] Obata K, Mukai K, Tsujimura Y, et al. Basophils are essential initiators of a novel type of chronic allergic inflammation. Blood 2007; 110: 913-20.

[29] Tsujimura Y, Obata K, Mukai K, et al. Basophils play a pivotal role in immunoglobulin-G-mediated but not immunoglobulin-E-mediated systemic anaphylaxis. Immunity 2008; 28: 581-9.

Juan Rivera

Laboratory of Molecular Immunogenetics, National Institute of Arthritis and Musculoskeletal and Skin Diseases, National Institutes of Health, Bethesda, Maryland, 20892,

E-mail: juan_rivera@nih.gov

(C) Juan Rivera.; Licensee Bentham Open.

This is an open access article licensed under the terms of the Creative Commons Attribution Non-Commercial License (http://creativecommons.org/ licenses/by-nc/3.0/) which permits unrestricted, non-commercial use, distribution and reproduction in any medium, provided the work is properly cited. 